\title{
Thermal-fluid characterization of alternative liquids of power transformers: a numerical approach
}

\author{
Ramón Lecuna, Fernando Delgado, Alfredo Ortiz, Pablo B. Castro, Inmaculada Fernandez \\ and Carlos J. Renedo \\ Mining and Energy Engineering School, Cantabria University \\ Bulevar Ronda Rufino Peón, s/n, 39316, Torrelavega, (Spain) \\ Phone/Fax number:+34 9422013 76/85; e-mail: ramon.lecuna@unican.es
}

\begin{abstract}
The transformers lifespan depends importantly on its refrigeration. Mineral oils perform this work in the majority of the power transformers. However, this type of coolant has two main drawbacks: low biodegradability and low ignition point. Several alternative liquids are being developed in order to overcome these drawbacks. This paper compares their thermal-fluid behavior with a mineral oil by means of several parameters, such as temperature, flow rate, fluids velocity, convective heat transfer coefficient (h) and the cooling criterion (P). These are calculated using the numerical results of the simulation of a 3D-model of a Low Voltage Winding that belongs to a power transformer with ONAN cooling. The software COMSOL Multiphysics has allowed the simulation of the geometry using a physical model in which buoyancies and viscous forces are the only considered establishing the natural convection. As a result of the comparison, it is clear that the mineral oil is the best coolant liquid. Among the alternative liquids, silicone oil would be the second best coolant fluid, followed by the synthetic and natural esters, respectively. On the other hand, it seems to be clear that the 3D simulations can be used to compare properly the cooling capacities of the liquids.
\end{abstract}

Index Terms —Dielectric liquids, fluid-dynamics, thermal analysis, power transformers, numerical analysis

\section{INTRODUCTION}

MINERAL oil is the most common option as a cooling and dielectric liquid in the majority of the power transformers worldwide. However, in cases where fire risk is an important concern, this type of liquid is not so recommendable. Fire resistant oils (with higher flash and fire points than those of the mineral oils) should be used. Environmental reasons are also supporting the development of new transformer oils with improved biodegradability, so that in the event of a failure or leakage the impact would be lower. Thus, the growing demands for improved fire safety and environmental sustainability have encouraged the research and development of alternative fluids.

The main research lines of these liquids are focused in silicone oils, natural and synthetic esters. The characterization of silicone oils and synthetic esters has been studied by a few authors [1-5]. However, the majority of the studies has been focused in the physicochemical characterization of some commercial natural esters, [6-8], or based on some specific crop (coconut, palm, rapeseed...) [9-10]. Finally, some authors have compared the main properties of these new fluids with mineral oil in order to evaluate their suitability [11].
On the other hand, there has been a lot of research about cooling improvement in power transformers. The reason is simple, high temperatures degrade the dielectric materials, oil and paper, shortening their lifespan. In order to ensure a long life for these machines, there are two types of approximations for the calculation of their temperature and velocity distributions: lumped parameter models and Computational Finite Element-based Tools (CFET). The first method provides fast and approximate results based on several simplifications and empirical data. By contrast, the second one is more accurate since it is based on the solution of the differential equations governing processes.

Several papers have been published in last decade using CFET. Nonetheless, we have to mention that the main goal of practically all these papers is the determination of the velocity and temperature profiles of a mineral oil inside a 2D section of one winding. For instance, Mufuta and Van den Buck described the flow pattern and its influence in the cooling of the windings of a disc-type transformer by means of dimensionless parameters (Nu, Re, Gr) applied on a 2D model [12]. Six years later, El Wakil et al. studied the heat transfer and fluid flow in two windings wound around a core of a stepdown 3-phase layer-type power transformer by means of the analysis of six different 2D-models [13]. In 2007, Rahimpur et 
al. calculated the influence of some parameters (heat loss, number of washers, height of the radiators and channel geometry) over temperatures distribution of a 2D-model of a natural convective cooled disc-type winding including block washers [14]. . Two years later, Smolka et al., in addition to perform a review about numerical simulations of the fluid flow, heat transfer and electromagnetic phenomena, presented an innovative 3D-coupled Computational Fluid Dynamics (CFD) and ElectroMAGnetic (EMAG) simulation of a 3-phase medium-power dry-type transformer [15]. In 2010, a 2Dmodel of a pass of a Low Voltage Winding (LVW) that belongs to a 3-phase disc-type transformer was simulated by Torriano et al. The main goal of this paper was to find the influence of different inlet conditions on the flow and temperature distributions. They also determined the location of the hot-spots in the winding [16]. More recently, in 2012, the same authors carried out a comparison between 2D and 3D models of the same geometry, thus determining the existence of three-dimensional fluid flow phenomena that cannot be obviated such as it occurs in the 2D-model [17]. The same year, Skillen et al. developed a 2D-model based on the geometry of Torriano's transformer with five passes in a column. The presence of hot-plumes in some horizontal ducts and the transmission of hot streaks from one pass to the next (flow coupling) were the main conclusions of this paper [18]. Again, in the same year, a 3-D model of a 15-kVA ONAN transformer was carried out by Rosillo et al. in which oil velocity profile and oil and winding temperature distribution were calculated and experimentally validated in accordance with the IEEE-1995 Loading Guide [19]. Finally, one year before, Gastelurrutia et al. presented slices of several ONAN distribution transformers (2D-models) in which the oil flow and the thermal distributions were numerically calculated, thus allowing the comparison of the results with the experimental ones [20].

All the papers mentioned in former paragraph use mineral oil as dielectric liquid. Moreover, the majority of the models used were performed in two dimensions in order to overcome computational limitations. This type of $2 \mathrm{D}$ analysis is discarded in this paper due to there is heat transfer in all directions of the volume of our model; also, this 2D analysis does not allow determinate the exact location of the hot spots. For that reason, a 3D-section of the cooling ducts of the LVW of a real power transformer is used in this paper. Even more, this geometry is simulated using a physical model in which buoyancies and viscous forces are the only considered establishing the natural convection. As a result of this simulation, a comparison of the main characteristics of a mineral oil and three alternative liquids (a silicone oil, a natural ester and a synthetic ester) is obtained. In order to carry out this work, a thermal-fluid analysis has been performed using flow rates, temperature and velocity distributions and parameters such as the traditional convective heat transfer coefficient (h) and the new one cooling criterion $(\mathrm{P})$.

Section two presents a brief geometrical description of the $3 \mathrm{D}$ model that is used. The third section introduces the numerical model considered. The studied parameters and the analysis methodology are presented in the fourth section. Simulation results and their comparison are shown in the fifth section. Finally, findings are presented in the last section.

\section{MODEL GEOMETRY DESCRIPTION}

The aforementioned comparison has been carried out by using a section of the LVW of a three-phase power transformer. In nominal regime, the electrical characteristics of this transformer are $14 \mathrm{MVA}, 66 / 6.3 \mathrm{kV}$, Dyn11 and ONAN cooling.

The self-explanatory Figure 1 (left side) and Figure 2 (bottom right corner) shows the three windings of a phase of a three-phase transformer: LVW in the inner part; onload tap winding in the outer part; finally, the High Voltage Winding in the middle of both of them.

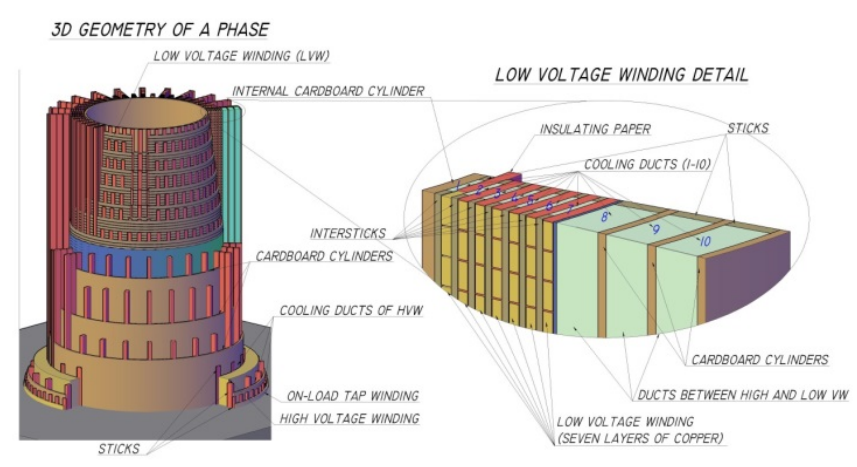

Figure 1. 3D geometry of one phase and detail of the LVW

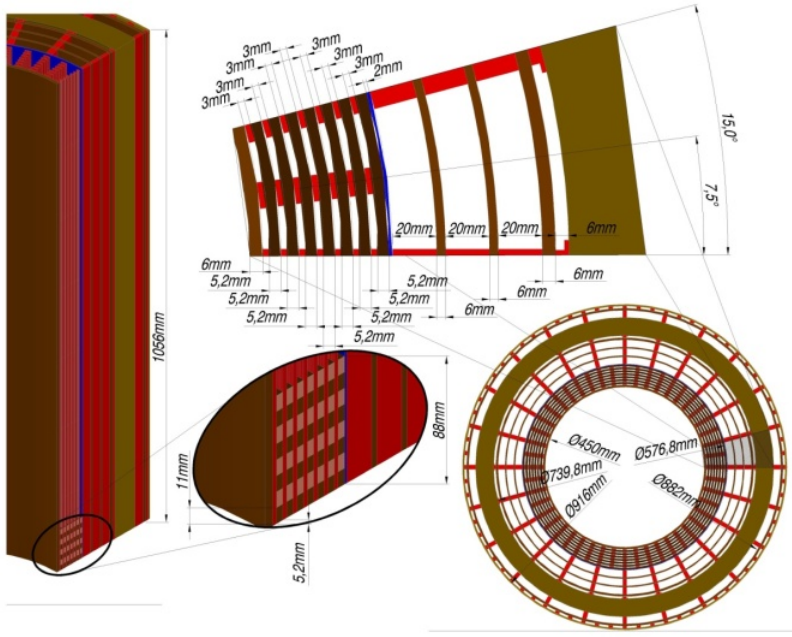

Figure 2. Plant dimensioning of a phase and detail of the LVW

The LVW, shown in 3D dimensions in the right side of Figure 1 and in 2D dimensions plan in the upper side of Figure 2, is composed of an internal cardboard cylinder (6 $\mathrm{mm}$ thick and $450 \mathrm{~mm}$ of inner diameter) surrounded by 7 concentric layers with 11 copper turns by layer. Each turn has 8 parallel plates (plate dimensions: $10.4 \mathrm{mmx} 4.6 \mathrm{~mm}$ ) that are wrapped with a dielectric paper of $0.3 \mathrm{~mm}$ width. The layers are separated by means of 48 wooden sticks and inter-sticks of $3 \mathrm{~mm}$ thick. This way, 48 cooling ducts of 7.5 degrees of amplitude are created between internal cylinder and first layer, other 48 cooling channels between first layer and second layer, and so on. Finally, the total height of the LVW is $1,056 \mathrm{~mm}$.

Self-explanatory Figure 3 allows understanding how the geometrical design has evolved to achieve the optimal 


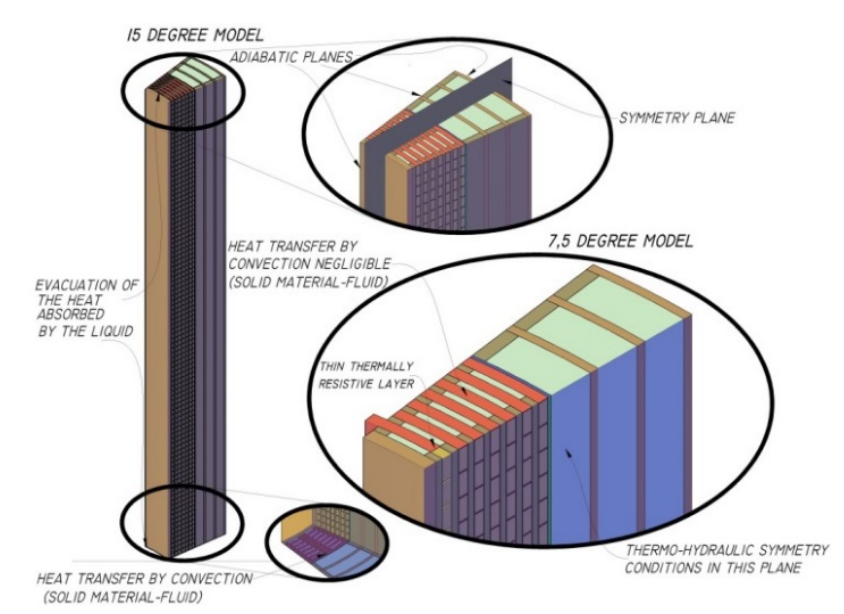

Figure 3. Geometrical evolution of the model

model for solving numerically. In fact, the results comparison of both models (15-degree model and 7.5degree model) allows to demonstrate that there are no significant differences between their temperatures and velocities distributions. This way, 7.5-degree model has been chosen.

Figure 3. Geometrical evolution of the model

This section presents the governing equations, the physical model and its boundary conditions, computational domain and mesh.

\subsection{GOVERNING EQUATIONS}

This study is based on the numerical solution of the momentum and continuity equations, (1) and (2) respectively. It also solves the heat transfer equation, which for a fluid is (3).

$$
\begin{gathered}
\rho(\boldsymbol{u} \cdot \nabla) \boldsymbol{u}=\nabla \cdot\left[-p \boldsymbol{I}+\mu\left(\nabla \boldsymbol{u}+(\nabla \boldsymbol{u})^{T}\right)-\frac{2}{3} \mu(\nabla \cdot \boldsymbol{u}) \boldsymbol{I}\right]+\boldsymbol{F} \\
\nabla \cdot(\rho \mathbf{u})=0 \\
\rho C_{p} \mathbf{u} \cdot \nabla \mathrm{T}=\nabla \cdot(\mathrm{k} \nabla T)+q
\end{gathered}
$$

The symbols $\rho, \boldsymbol{u}, p, \mathbf{I}, \mu, \mathbf{F}, \mathrm{C}_{\mathrm{p}} \mathrm{T}$ and $q$ of (1), (2) and (3) are density, velocity vector, pressure, identity matrix, dynamic viscosity, body force vector, specific heat capacity, temperature and unitary heat transfer, respectively.

\subsection{PHYSICAL MODEL AND BOUNDARY CONDITIONS}

All exterior solid walls of the geometric model are considered adiabatic surfaces (see (4) in which $\mathrm{k}$ is the thermal conductivity) apart from the bottom solid surfaces. Also, the internal energy increase of the coolant between the oil inlets and outlets is considered (see details in left side of Figure 3).

$$
-\boldsymbol{n} \cdot(-k \nabla T)=0
$$

Convective cooling between the bottom solid surfaces and the oil is supposed, considering the inlet temperature of the liquid in the ducts as oil temperature $\left(\mathrm{T}_{\text {oil,inlet }}=35^{\circ} \mathrm{C}\right.$ ) (see detail in bottom left side of Figure 3) (see (5) in which $n$ is the normal vector to boundary surface).

$$
-\boldsymbol{n} \cdot(-k \nabla T)=h \cdot\left(T-T_{\text {oil,inlet }}\right)
$$

No-slip condition is considered in the contact surfaces between oil and the solid surfaces in the ducts (see (6)).

$$
\boldsymbol{u}=0
$$

Natural convection due to oil decreasing density with the increase of the temperature is the main phenomenon that determines the thermodynamic behavior inside the ducts (see (7) in which $g$ is the gravity acceleration). Also, boundary conditions in inlets and outlets of the cooling channels are pressure-based (see (8) for inlet pressure and (9) for outlet pressure in which $T_{\text {oil, } \infty}$, and $H$ are the reference temperature of the model $\left(35^{\circ} \mathrm{C}\right)$ and the total height of the ducts, respectively).

$$
\begin{gathered}
F_{z}=-g \cdot \rho(T) ; \rho(\boldsymbol{u} \cdot \nabla) \boldsymbol{u}= \\
\nabla \cdot\left[-p \boldsymbol{I}+\mu\left(\nabla \boldsymbol{u}+(\nabla \boldsymbol{u})^{T}\right)-\frac{2}{3} \mu(\nabla \cdot \boldsymbol{u}) \boldsymbol{I}\right]+\boldsymbol{F} \\
p=\rho\left(T_{o i l, \infty}\right) \cdot g \cdot H ;\left[\mu\left(\nabla \boldsymbol{u}+(\nabla \boldsymbol{u})^{T}\right)-\frac{2}{3} \mu(\nabla \cdot \boldsymbol{u}) \boldsymbol{I}\right] \cdot \boldsymbol{n} \\
=0 \\
p=0
\end{gathered}
$$

Thermal-fluid symmetry has been modeled using (10) and (11) (see detail in right-side of Figure 3).

$$
\begin{gathered}
-\boldsymbol{n} \cdot(-k \nabla T)=0 \\
\boldsymbol{u} \cdot \boldsymbol{n}=0 ; \boldsymbol{K}-(\boldsymbol{K} \cdot \boldsymbol{n}) \boldsymbol{n}=\mathbf{0}
\end{gathered}
$$

where

$$
\boldsymbol{K}=\left[\mu\left(\nabla \boldsymbol{u}+(\nabla \boldsymbol{u})^{T}\right)\right] \boldsymbol{n}
$$

The wrapping paper is considered mathematically as a thin thermally resistive layer whose thermal behavior is modeled according (12) in which $k_{p}, \mathrm{~T}_{\mathrm{i}}, \mathrm{T}_{\mathrm{o}}$ and $\mathrm{d}_{\mathrm{p}}$ are the conductivity, the temperatures in the inside and outside surfaces and the thickness of the paper, respectively (see detail in right-side of Figure 3).

$$
q=-k_{p} \frac{\left(T_{i}-T_{o}\right)}{d_{p}}
$$

Finally, a uniform volumetric heat source is considered in the copper domain using the Joule losses that are measured in a short-circuit test at $75^{\circ} \mathrm{C}$ of the power transformer (see (13) in which $\mathrm{P}_{\text {Joule }}$ and $\mathrm{V}$ are the copper loses in the 3-phase LVW and the volume of this winding, respectively).

$$
\mathrm{Q}=\frac{\mathrm{P}_{\text {Joule }}}{\mathrm{V}}
$$

The above physical model has been solved via the "Conjugate Heat Transfer" module of the commercial finite elements-based software Comsol Multiphysics v4.3a. This module allows combining the heat equation with either laminar or turbulent flow. The similarity between the geometric and physical models of our article and ElMorshedy's paper [21], in addition to the higher viscosities of our coolants (water is the coolant of the reference article), allows us to establish that the heat transfer is going 


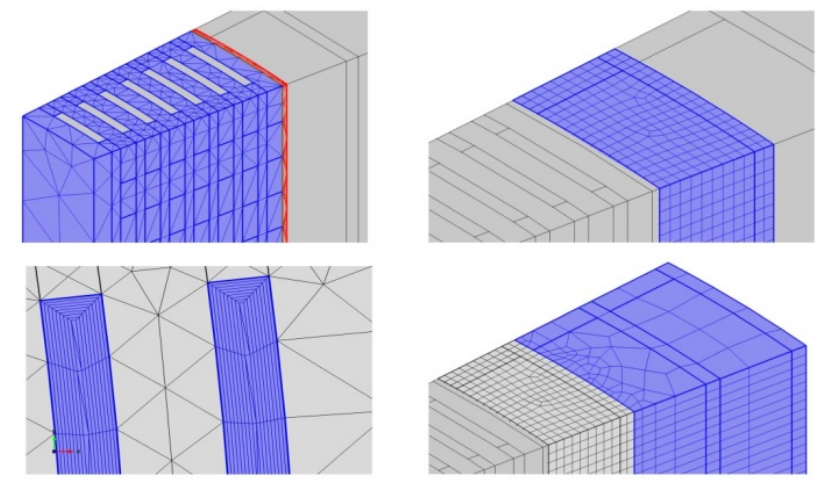

Figure 4. Computational mesh of the solid and fluid domains

to be carried out by natural convection under laminar flow regime.

\subsection{COMPUTATIONAL DOMAIN AND MESH}

The computational domain considers both the liquid and solid parts of the geometry in order to calculate the temperature distribution in the entire model and the fluid behavior inside the channels. The simulations took between 90 and 120 minutes using a workstation with two processors at $2.66 \mathrm{GHz}$ and 48 Gbytes of RAM with a convergence criterion of 10-4 for the residuals values.

Initially, in the meshing convergence study, several mesh types with different meshing densities are studied, thus obtaining several configurations with similar solutions. In this paper, among these last configurations, the simplest one from the computational standpoint is selected.

Three types of mesh and different element sizes were used depending on the level of accuracy required. Regarding the solid domain, it was meshed with a free tetrahedral grid of 240,642 elements and a very thin tetrahedral transitional mesh of 332,373 elements between this domain and the first wide channel (See blue and red volumes in upper left-side of Figure 4). 92,162 extra-thin hexahedral elements were generated by means of a sweep method applied between the bottom and upper faces of the first channel (upper right-side of Figure 4). The other two wide channels were meshed with the same method but with a coarser element size, thus generating 127,574 elements (bottom right-side of Figure 4). Finally, each of the seven narrow channels was meshed by means of eight boundary layers of $0.19 \mathrm{~mm}$ width, thus generating 264,570 tetrahedral elements (Bottom left-side of Figure 4).

\subsection{MATERIAL PROPERTIES}

Figure 5 presents the four physical characteristics of the five transformer liquids studied in this paper by means of both their mathematical expressions and graphical plots in the range of operating temperatures. These five dielectric liquids are: one mineral oil, two silicone oils (one with High Kinematic Viscosity (50 cSt, HKV) and other with Low Kinematic Viscosity (25 cSt, LKV)), one natural ester and one synthetic ester. The graphs are calculated using data that are available in public datasheets since all of the liquids are commercial oils.

The densities of these liquids decrease linearly with the temperature. In the case of the viscosities, those of the 290 alternative liquids have higher values than mineral oil at low temperatures, except the silicone oil with low viscosity. However, this property diminishes exponentially with the temperature, thus being practically equal at high temperatures for all the liquids, except the silicon oil with high viscosity.

The winding layers are made of copper conductors that are individually wrapped with insulation paper. Also, these layers and four cardboard cylinders are separated by wooden sticks and inter-sticks. The physical properties ( $\rho$, $k, C_{p}$ ) that are needed for all these materials in order to use them in the simulations are shown in Table 1 . These properties are assumed to be constant with temperature.

Convective heat transfer coefficient at the bottom is calculated considering a horizontal plate with down external natural convection with oil at $\mathrm{T}_{\text {oil,inlet }}=35^{\circ} \mathrm{C}$.

Table1. Physical properties of solid materials

\begin{tabular}{lccc}
\hline & $\begin{array}{c}\rho \\
{\left[\mathrm{kg} / \mathrm{m}^{3}\right]}\end{array}$ & $\begin{array}{c}\mathrm{k} \\
{[\mathrm{W} /(\mathrm{m} \mathrm{K})]}\end{array}$ & $\begin{array}{c}\mathrm{C}_{\mathrm{p}} \\
{[\mathrm{J} /(\mathrm{kg} \mathrm{K})]}\end{array}$ \\
\hline Copper & 8,700 & 400 & 385 \\
Paper & 930 & 0.19 & 1,340 \\
Cardboard & 1,150 & 0.25 & $2,093.5$ \\
Wood & 418.5 & 0.15 & 2,720 \\
\hline
\end{tabular}

\section{STUDY METHODOLOGY}

The coefficient $h$ can be used to determine the cooling capacity of the fluids in order to carry out a thermal comparison. This comparison can be performed using the alternative parameter $P$. Equations (14) and (15) present the way to calculate them by using the simulation results.

$$
\begin{gathered}
h=\frac{Q_{c h}}{A \times\left(T_{\text {avg,surface }}-T_{\text {oil }, \infty}\right)} \\
P=\frac{C_{p} \times k \times \beta}{v} \\
Q_{c h}=\mathrm{C}_{\mathbf{p}, \mathbf{a v g}} \times \dot{\mathbf{m}}_{c h} \times\left(\mathrm{T}_{\text {avg,outlet }}-\mathrm{T}_{\text {oil,inlet }}\right)
\end{gathered}
$$

The coefficient $h$ is an experimentally determined parameter which depends on many variables such as the surface geometry, the nature of fluid motion and the physical properties of the fluid. This coefficient allows determining the efficiency of the heat transfer between a solid surface and a fluid. The higher this number is, the better the heat transfer by convection is. In this paper, it is calculated according (14) in which $\mathrm{Q}_{\mathrm{ch}}, \mathrm{A}, \mathrm{T}_{\mathrm{avg}, \text { surface, }}$ are the heat transfer between the copper and oil in each channel, the heat transfer area of this channel and the average temperature of this area, respectively. $Q_{c h}$ is previously estimated by means of the calculation of the internal energy increase of the fluid between inlet and outlet surfaces (see (16) in which the fluid properties $C_{p \text {,avg }}, \dot{m}_{c h}$, and $T_{a v g, \text { outlet }}$ and $\mathrm{T}_{\text {oil, inlet }}$ are considered). The average heat capacity, the flow rate and the average temperature at the outlets of the ducts are the meanings of the first three properties. Also, the oil temperature in the ducts inlets $\left(T_{\text {oil,inlet }}\right)$ is assumed as reference temperature $\left(\mathrm{T}_{\mathrm{oil}, \infty}\right)$. 

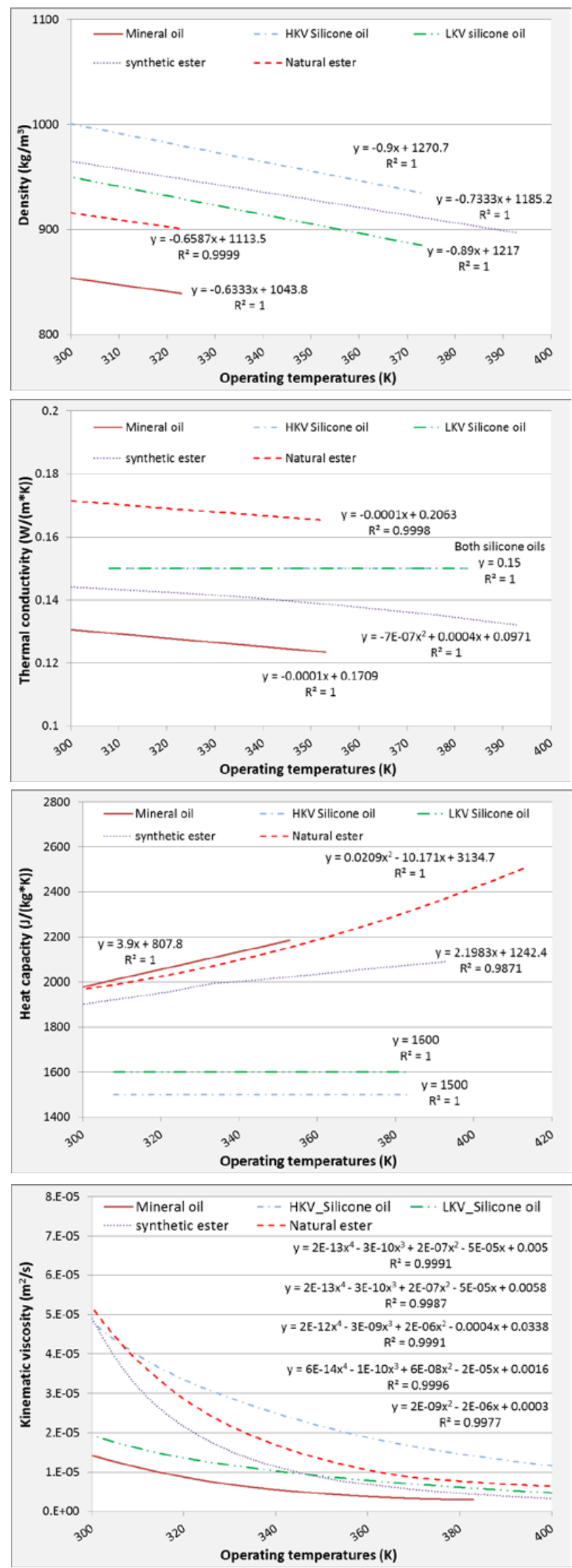

Figure 5. Physical properties of the dielectric liquids
The coefficient $P$ depends on four physical properties of the fluids that vary with temperature (See (16) in which $\beta$ and varethe thermal expansion coefficient and the kinematic viscosity, respectively) and it is used in experimental studies to determine the heat transfer capacity of different oils [22]. Thus, the higher $\mathrm{P}$ is, the lower the average temperature of the fluid in each channel is. In each channel, it is calculated by means of (15) using the average values of the four properties.

\section{RESULTS}

The model validation is shown in the first subsection. In next subsection, temperatures and flow rates of the ducts are presented. Finally, in third subsection, h a P results are compared.

\subsection{MODEL VALIDATION}

The comparison of the average velocities of the ducts 26, shown in Table 2, with those of the El-Morshedy's article [21] confirms the hypothesis that is initially supposed: the flow regime of all the studied liquids is laminar in those channels of our model that are similar, from the physical and geometric standpoint, to that of the aforementioned paper.

Table 2. Average velocities in the ducts ( $\mathrm{v}_{\text {avg,duct }}$ )

\begin{tabular}{|c|c|c|c|c|c|c|}
\hline & & \multicolumn{5}{|c|}{$\mathrm{v}_{\text {avg,duct }}(\mathrm{mm} / \mathrm{s})$} \\
\hline & & $\begin{array}{c}\text { Mineral } \\
\text { oil }\end{array}$ & $\begin{array}{c}\text { HKV } \\
\text { Silicone } \\
\text { oil }\end{array}$ & $\begin{array}{c}\text { LKV } \\
\text { Silicone } \\
\text { oil }\end{array}$ & $\begin{array}{l}\text { Synthetic } \\
\text { ester }\end{array}$ & $\begin{array}{l}\text { Natural } \\
\text { ester }\end{array}$ \\
\hline \multirow{10}{*}{ Channels } & 1 & 6.77 & 4.59 & 6.72 & 4.56 & 3.97 \\
\hline & 2 & 9.41 & 6.04 & 9.05 & 6.35 & 5.35 \\
\hline & 3 & 9.72 & 6.33 & 9.41 & 6.6 & 5.6 \\
\hline & 4 & 9.77 & 6.40 & 9.48 & 6.64 & 5.65 \\
\hline & 5 & 10.13 & 6.57 & 9.81 & 6.86 & 5.82 \\
\hline & 6 & 9.47 & 6.04 & 9.14 & 6.37 & 5.37 \\
\hline & 7 & 8.27 & 4.95 & 7.88 & 5.37 & 4.45 \\
\hline & 8 & 9.52 & 7.07 & 9.96 & 6.16 & 5.72 \\
\hline & 9 & 0.35 & 0.33 & 0.38 & 0.26 & 0.26 \\
\hline & 10 & 0.14 & 0.14 & 0.15 & 0.11 & 0.1 \\
\hline
\end{tabular}

\subsection{TEMPERATURES AND FLOW RATES}

As initial point, it is necessary to point out that there are two types of channels from the geometrical standpoint: those ducts with narrow cross-section (channels 1-7), and those with wide cross-section (channels 8-10). It is clear that this geometrical feature has a major influence in the flow rates and velocities of the channels, therefore, in their temperatures (See Tables 2 and 3). Also, we can see that the velocities of those fluids with higher viscosities in the operating temperature range (ester-based liquid sand HKV silicone oil) are lower than those of the other two liquids, both in narrow and wide channels.

Table 3 shows the maximum temperature of the geometry ( $\left.\mathrm{T}_{\text {max,model }}\right)$, the $\mathrm{T}_{\text {avg,outlet }}$ and the $\dot{\mathrm{m}}_{c h}$ in all the ducts for all the liquids. In relation to the former, it can be 


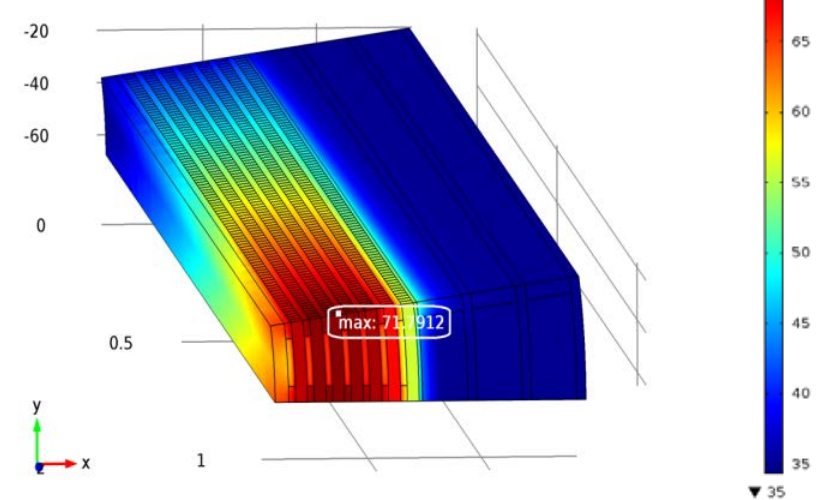

Figure 6. Location of hot-spots 409
From here, those channels with similar thermal behavior are going to be studied: the channels 2-5 have similar average temperatures inside them $\left(\mathrm{T}_{\text {avg,ch }}\right)$ and similar $\mathrm{T}_{\text {avg,outlet }}$ for the same fluid (See Table 3 and Figure 7). Also, these channels have the highest temperatures if the same liquid is considered.

Then, it is perceived that the use of alternative fluids gives rise to an increase both in $\mathrm{T}_{\text {avg,outlet }}$ and $\mathrm{T}_{\text {avg,ch. }}$. In both temperatures, the HKV silicone oil has the higher increment (36.1\% and $25.4 \%$ respectively). On the other hand, the lower increment is in the case of LKV silicone oil (8.5\% and $6.6 \%$ respectively). The ester-based oils have intermediate increments to those of the above. It is also remarkable that the higher is the $T_{\text {avg,outlet, }}$, the smaller is $T_{\text {avg,outlet }}-T_{\text {avg,ch. }}$ That is, higher temperature distributions in the ducts are obtained with the new liquids.

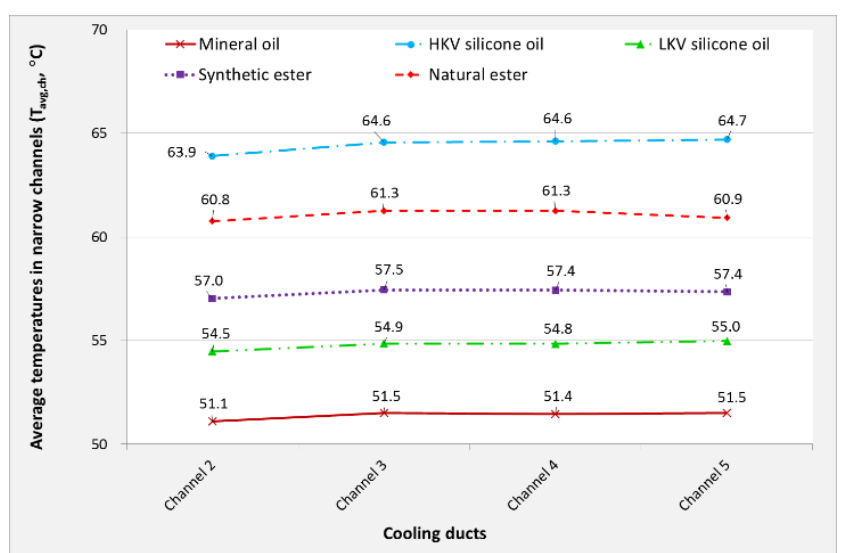

Figure 7. Average temperatures in narrow channels

Regarding the flow rates, shown in Table 3, it can be observed that mineral and LKV silicone oils have similar flow rates. In the range of operating temperatures, they both have similar viscosities. However, the mineral oil has higher specific heat capacity (and its value increases with the temperature) than that of the LKV silicone oil (its value is constant with the temperature). This fact explains why mineral oil is heated less than the LKV silicone-based fluid. As a result, the density variation of the mineral oil is smaller than that of the alternative liquid, thus obtaining a slightly lower flow rate. On the other hand, the ester-based liquids and HKV silicone oil have lower flow rates due to, mainly, their high viscosities in the aforementioned temperature range. In the case of ester-based fluids, the  400 the temperature does not completely offset the high viscous 401 stresses. This effect is even more important in the case of 402 the LKV silicone oil since the heat capacity is constant in 403 the range of the operating temperatures. So, the cooling 404 capacities of these last three alternative liquids are worse 405 than those of the mineral and LKV silicone oils: there are 406 higher temperatures in the winding, as can be seen in Table $407 \quad 3$ and Figure 7.

\subsection{COOLING CAPACITY OF THE FLUIDS}

Figure 8 shows the average values of the coefficients $h$ of the five studied liquids in the channels two to five. As can be seen in this Figure, the higher coefficient $h$ belongs to 
412 mineral oil, with values in the range of 30 to $40 \mathrm{~W} /\left(\mathrm{m}^{2} \mathrm{~K}\right)$. 413 The other coefficients are lower in a 13\% (LKVsilicone 414 oil), 22\% (synthetic ester), 32\% (natural ester)and 40\% 415 (HKV silicone oil),approximately.

416

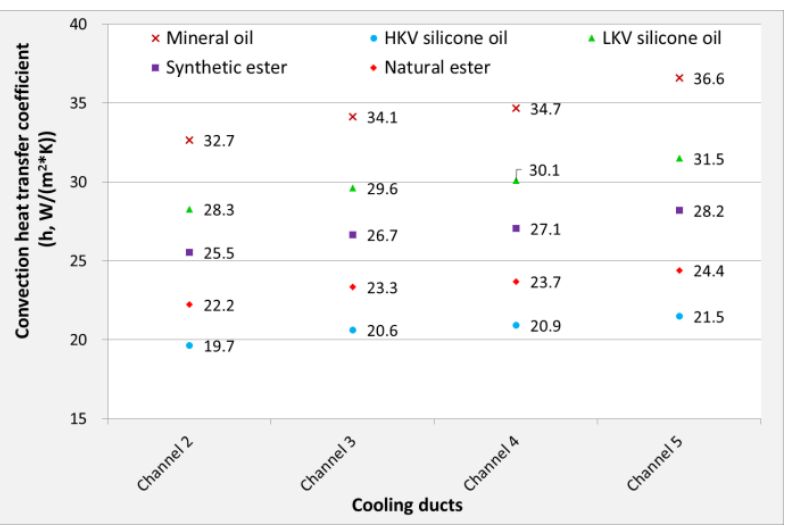

Figure 8. Average convection heat transfer coefficient of the liquids

417

418

419

420

421

422

423

424

425
In the same way that in the Figure 8, the average values of the $P$ of the five studied liquids in the channels two to five are shown in Figure 9. Again, according this parameter, mineral oil is the best coolant, followed by the LKV silicone oil, synthetic and natural esters, and HKV silicone oil (27\%, 43\%, $48 \%$ and $68 \%$ smaller values than mineral oil, respectively).

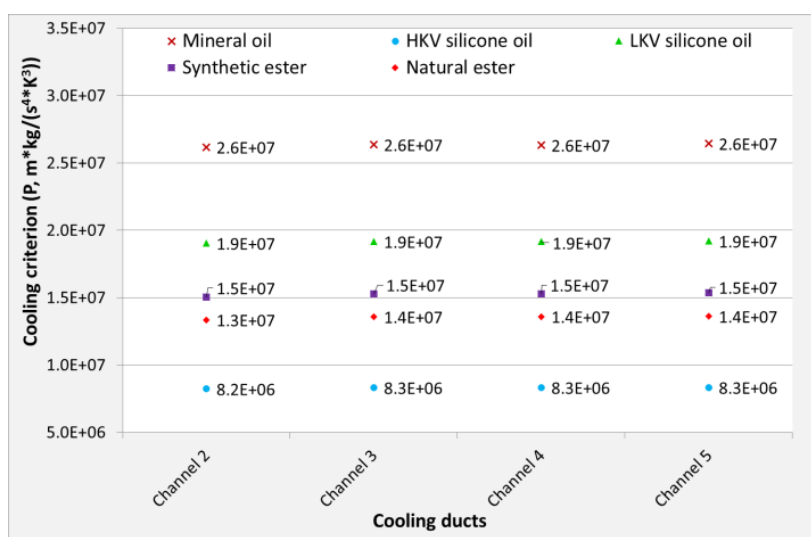

Figure 9. Average cooling criterion $(\mathrm{P})$ of the liquids

There is an important difference between both parameters: $P$ only considers the physical properties of the fluids and $h$ also considers the flow characteristics in each channel. This fact explains why the values of $h$ vary with the channel. However, the $P$ values do not practically change with the channel. This also explains the higher differences in the cooling capacities between alternative liquids and the mineral oil using $P$ instead of $h$. Nonetheless, it seems to be clear that the new parameter can also be used to classify the fluids according their refrigeration capacities.

\section{CONCLUSIONS}

In the present study, the thermal-fluid behavior of five dielectric liquids (four alternative fluids and a traditional one) have been studied. In addition to the flow rates, velocities and temperatures patterns are analyzed in order to establish thermal-fluid differences. Also, $h$ and $P$ are used to compare their cooling capacities. All the above is calculated using the numerical results of a 3D-model of a LVW of a transformer with ONAN cooling. This type of cooling has been performed by means of a physical model in which buoyancies and viscous forces are only considered.

As a result of the analysis of the aforementioned parameters, among the studied liquids, it is clear that the mineral oil is the better coolant, followed by the LKV silicone oil, synthetic ester, natural ester, and HKV silicone oil. It is remarkable that the viscosities of the biodegradable liquids and the HKV silicone oilare so high (especially with low temperatures) that their cooling capacities are negatively affected in an important manner, especially in the case of the HKV silicone oil. Regarding the LKV silicone oil, in comparison with the mineral oil, its main drawback is its worse specific heat capacity.

It seems to be clear that the $3 \mathrm{D}$ simulations can be used to compare properly the cooling capacities of the liquids using traditional parameters such as the convection heat transfer coefficient or new ones, such as the cooling criterion.

\section{ACKNOWLEDGMENT}

The research leading to these results has received funding from multiple sources during years but we would specifically like to acknowledge the support received in the later stages from the Spanish Plan Estatal de I+D under the grant agreement DPI2013-43897-P.

\section{REFERENCES}

[1] E. Gockenbach, H. Borsi, Natural and synthetic ester liquids as alternative to mineral oil for power transformers. Presented at Annual Report Conference on Electrical Insulation and Dielectric Phenomena, CEIDP 2008, Quebec City, QC, 2008, pp. 521-524.

[2] H. Borsi, E. Gockenbach, Properties of ester liquid midel 7131 as an alternative liquid to mineral oil for transformers. Presented at IEEE International Conference on Dielectric Liquids, ICDL 2005, Coimbra, 2005, pp. 377-380.

[3] R. Eberhardt, H. M. Muhr, W. Lick, B. Wieser, R. Schwarz, G. Pukel, Partial discharge behaviour of an alternative insulating liquid compared to mineral oil. Presented at IEEE International Symposium on Electrical Insulation,ISEI 2010, San Diego, CA, 2010.

[4] H. Borsi, "Dielectric behavior of silicone and ester fluids for use in distribution transformers," IEEE Trans Electr Insul, vol. 26, pp. 755-762, 10 September 1990 through 14 September 1990, 1991.

[5] H. Kuwahara, K. Tsuruta, H. Munemura, T. Ishi, H. Shiomi, "Partial discharge characteristics of silicone liquids," IEEE Trans Electr Insul,vol. EI-11, pp. 86-91, 1976.

[6] T. V. Oommen, C. C. Claiborne, E. J. Walsh, J. P. Baker, New vegetable oil based transformer fluid: Development and verification. Presented at IEEE Conference on Electrical Insulation and Dielectric Phenomena, BC, Can, 2000, pp. 308-312.

[7] C. C. Claiborne, T. V. Oommen, E. J. Walsh, "Specification issues associated with the development of an agriculturally based biodegradable dielectric fluid," ASTM Spec. Tech. Publ., pp. 37-46, 15 March 1999 through 15 March 1999, 2000.

[8] P. Boss, T. V. Oommen, New insulating fluids for transformers based on biodegradable high oleic vegetable oil and ester fluid. Presented at IEE Colloq. Dig., pp. 39-48, 1999.

[9] U. U. Abdullahi, S. M. Bashi, R. Yunus, Mohibullah, H. A. Nurdin, The potentials of palm oil as a dielectric fluid. Presented at National Power and Energy Conference, PECon 2004, Kuala Lumpur, 2004, pp. 224-228. 
[10] J. Li, S. Grzybowski, Y. Sun, X. Chen, Dielectric properties of rapeseed oil paper insulation, 2007 Annual Report - Conference on Electrical Insulation and Dielectric Phenomena, CEIDP, Vancouver, BC, 2007, pp. 500-503.

[11] I. Fernández, A. Ortiz, F. Delgado, C. Renedo, S. Pérez, "Comparative evaluation of alternative fluids for power transformers," Electr. Power Syst. Res., vol. 98, pp. 58-69, 2013.

[12] J. -. Mufuta, E. Van Den Bulck, "Modelling of the mixed convection in the windings of a disc-type power transformer," Appl. Therm. Eng., vol. 20, pp. 417-437, 2000.

[13] N. El Wakil, N. -. Chereches, J. Padet, "Numerical study of heat transfer and fluid flow in a power transformer,” Int. J. Therm. Sci., vol. 45, pp. 615-626, 2006.

[14] E. Rahimpour, M. Barati and M. Schäfer, “An investigation of parameters affecting the temperature rise in windings with zigzag cooling flow path,” Appl. Therm. Eng., vol. 27, pp. 1923-1930, 2007.

[15] J. Smolka, O. Bíró, A. J. Nowak, "Numerical simulation and experimental validation of coupled flow, heat transfer and electromagnetic problems in electrical transformers," Arch. Comput. Methods Eng., vol. 16, pp. 319-355, 2009

[16] F. Torriano, M. Chaaban, P. Picher, "Numerical study of parameters affecting the temperature distribution in a disc-type transformer winding," Appl. Therm. Eng., vol. 30, pp. 2034-2044, 2010.

[17] F. Torriano, P. Picher, M. Chaaban, "Numerical investigation of 3D flow and thermal effects in a disc-type transformer winding," Appl. Therm. Eng., vol. 40, pp. 121-131, 2012.

[18] A. Skillen, A. Revell, H. Iacovides, W. Wu, "Numerical prediction of local hot-spot phenomena in transformer windings," Appl. Therm. Eng.,vol. 36, pp. 96-105, 2012.

[19] M. E. Rosillo, C. A. Herrera and G. Jaramillo, "Advanced thermal modeling and experimental performance of oil distribution transformers," IEEE Trans Power Delivery, vol. 27, pp. 1710-1717, 2012.

[20] J. Gastelurrutia, J. C. Ramos, G. S. Larraona, A. Rivas, J. Izagirre, L. Del Río, "Numerical modelling of natural convection of oil inside distribution transformers,” Appl. Therm. Eng., vol. 31, pp. 493-505, 2011. [21] S. E. D. El-Morshedy, A. Alyan, L. Shouman, "Experimental investigation of natural convection heat transfer in narrow vertical rectangular channel heated from both sides," Exp. Therm. Fluid Sci., vol. 36, pp. 72-77, 2012.

[22] C. Perrier, A. Beroual, J. -. Bessede, "Improvement of power transformers by using mixtures of mineral oil with synthetic esters," IEEE Trans. Dielectr. Electr. Insul., vol. 13, pp. 556-564, 2006.

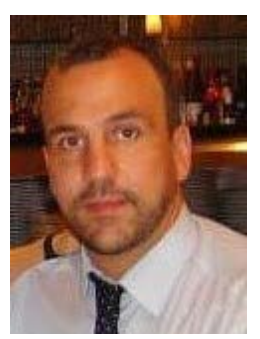

Ramón Lecunawas born in Torrelavega, on July 14, 1967. He received the M.Sc. degree in industrial engineering in 2000 and he is currently pursuing the Ph.D. degree from the University of Cantabria (UC), Spain. Currently, he is Assistant Professor in the Electrical and Energy Engineering Department of the UC. He has published 1 work in international conferences. Finally, his main research topic is currently the study of the alternative dielectric liquids in power transformers.

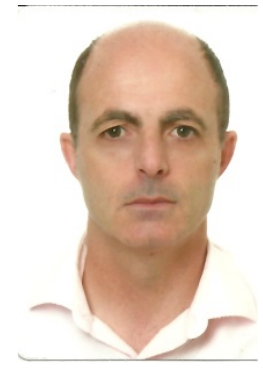

Fernando Delgado was born in Santander, on March 26, 1968. He received the M.Sc. degree in industrial engineering in 1998 and the Ph.D. degree in 2011 from the University of Cantabria (UC), Spain. Currently, he is Associate Professor in the Electrical and Energy Engineering Department of the UC. He has published over 25 works in international conferences and 13 papers in journals included in the Journal of Citation Report. Finally, his main research topic is currently the

study of the alternative dielectric liquids in power transformers.

550

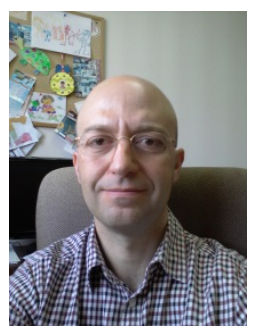

Alfredo Ortiz was born in Santander, on September 9, 1971. He received the M.Sc. degree in industrial engineering in 1997 and the Ph.D. degree in 2005 from the University of Cantabria (UC), Spain. Currently, he is Associate Professor and the Head of Electrical and Energy Engineering Department at the UC. He has published six chapters in international books, over 50 works in international conferences and XX papers in journals included in the Journal of Citation Report. Finally, his main research topic is currently the study of the alternative dielectric liquids in power transformers.

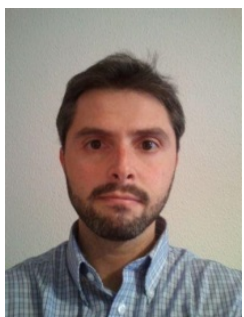

Pablo B. Castrowas born in Gijón, on July 12, 1979. He received the M.Sc. degree in industrial engineering in 2004 and the Ph.D. degree in 2011 from the University of Valladolid (UVA), Spain. Currently, he is Assistant Professor of Electrical and Energy Engineering Department at the UC. He has published 10 works in international conferences and 7 papers in journals included in the Journal of Citation Report. Finally, his main research topic is currently computational fluid dynamics and numerical heat transfer, renewable energies and energy efficiency.
552

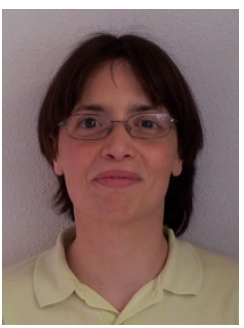

Inmaculada Fernández was born in Zaragoza, on July 31, 1981. He received the M.Sc. degree in chemical engineering in 2004 and the Ph.D. degree in 2009 from the University of Cantabria (UC), Spain. Currently, he is Assistant Professor in the Electrical and Energy Engineering Department of the UC. He has published two chapters in international books, over 20 works in national and international conferences and 9 papers in journals included in the Journal of Citation Report. Finally, his main research topic is the energy saving.

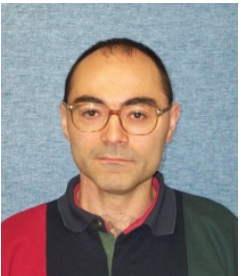

Carlos J. Renedowas born in Santander, on November 03, 1969. He received the M.Sc. degree in industrial engineering in 1997 and the Ph.D. degree in 2002 from the University of Cantabria (UC), Spain. Currently, he is Associate Professor in the Electrical and Energy Engineering Department of the UC and Vicedean of the School of Industrial Engineering and Telecommunications. He has published over 50 works in international conferences and 24 papers in journals included in the Journal of Citation Report. Finally, his main research topic is the energy saving. 